\title{
Thermo-Hydraulic Behavior of Water Cooling Channel Subjected to Constant Heat Flux during Pressure Reduction Transient in its Cooling System
}

\author{
Akram W. Ahmed Ezzat, Ph.D \\ Asst. prof. Dept. of Mech. Eng. \\ University of Baghdad
}

\author{
Emad W. Nayyef \\ Dept. of Mech. Eng. \\ University of Baghdad
}

\begin{abstract}
Heat transfer parameters of concentric heat source cooling channel exposed to pressure reduction transient is studied experimentally and theoretically. The heat source is of constant heat flux cooled by upward flowing water in concentric channel. The heat source is located inside cylindrical shape tube which is fixed in an annular vertical channel. The cooling water pressure reduction transient is ensured by different shape disturbance functions. The theoretical investigation involved a mathematical modeling for axially, symmetric, simultaneously developing laminar water flow in a vertical annulus. The mathematical model is based on one dimensional flow. The boundary conditions of the studied case are based on adiabatic outer wall while the inner wall is subjected to a constant heat flux for upwards flow. The heat \& mass balance equation derived for specified element of bulk water within the annulus, is solved to determine the variation of bulk water temperature, heat transfer coefficient, clad surface temperature and the boiling safety factor based on clad surface temperature versus length and time during transient course. The present theoretical work covers heat flux of $46345 \mathrm{~W} / \mathrm{m}^{2}$, channel inner to outer diameter ratio of 0.8 , water sub-cooled degree in the channel inlet ranging $\left(20-30^{\circ} \mathrm{C}\right)$, heat source length of 0.65 , water pressure at channel inlet of 1.3 bars and pressure reduction transient according to step, ramp and sinusoidal shape disturbance function (1.3- 1.0) bars. The experimental investigation included a set of experiments carried out to investigate the temperature variation along the heat source for step, ramp and sinusoidal pressure reduction transients in cooling system during and after reaching the steady state condition.
\end{abstract}

\section{Keywords}

Pressure reduction, CHF prediction, Sub-cooled flow boiling, Heat transfer parameters, nucleate boiling and concentric annular channel.

\section{INTRODUCTION}

Thermal hydraulic systems may be exposed to phenomena that may cause boiling in its different forms. The main initiators of these phenomena are sudden increased power, pressure reduction or coolant flow rate reduction which causes the so-called poor heat transfer. Possible improvement occurs for the heat transfer coefficient, in the area called nucleate boiling but this may lead to critical region at any time when it turned into a film boiling region during which is the most dangerous area accompanied by poor heat transfer coefficient that leads to malfunctioned heat generation systems, see figure (1),[2]. The transient boiling phenomenon sometimes occurs in the steps of startup and shut-down of the boiling systems. Transient boiling systems could be categorized into three types of transients: power transients, flow transients and pressure transients. In this paper, the effect of pressure transient will be investigated in boiling systems. Pressure transient occurs when the local pressure in the cooling channel varies with time. Therefore such studies will be of interest in engineering safety analysis of heat generations systems subjected to transient pressure reduction disturbance in their cooling systems. This disturbance will affect the heat removal efficiency of the coolant due to phase change accompanying pressure reduction. An example of such transients is small pipe break in nuclear power systems which affect fluid pressure rather than its velocity in the cooling channels and cause adverse boiling crisis in their cooling systems. Another example related to boiling water reactor (BWR) safety systems in which the nuclear safety systems is added to prevent or mitigate environmental and health hazards in the event of accident or natural disaster. However, unlike a pressurized water reactor which contains no steam in the reactor core, a sudden increase in BWR steam pressure (caused, for example, by the actuation of the main steam isolation valve (MSIV) from the reactor) will result in a sudden decrease in the proportion of steam to liquid water inside the reactor. The increased ratio of water to steam will lead to increased neutron moderation, which in turn will cause an increase in the power output of the reactor. This type of event is referred to as a "pressure transient". Most of the applications for this topic are related to engineering safety analysis of heat generation systems in process plants and power generation systems which are mainly utilized in different industrial sectors.[1]

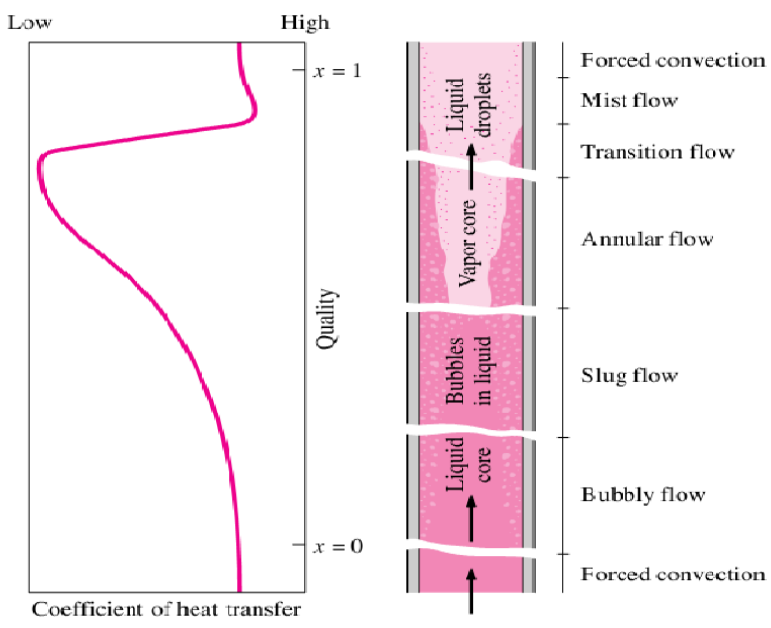

Fig (1): Flow boiling in a vertical tube (Collier 1981).

Several theoretical and experimental works are related to our research. Kwang et al. investigated transition boiling mechanism to predict transition boiling heat flux realistically for forced convection transition boiling. This model was 
based on a postulated multi-stage boiling process occurring during the passage time of the elongated vapor blanket specified at a critical heat flux (CHF) condition. The model predictions were compared with some available experimental transition boiling data given as the steady-state or transient boiling curves. Also they investigated the parametric effects of pressure, mass flux, inlet sub-cooling on the transition boiling heat transfer[3]. Gungor and Winterton studied flow boiling heat transfer for saturated and sub-cooled conditions using vertical and horizontal flow. The study is developed with the aid of a large data bank[4]. Prodanovic et al. studied the relation of boiling heat transfer process with experimentally observed bubble behavior during subcooled flow boiling of water in a vertical heated annulus. They explained the transition from partial to fully developed flow boiling with regard to bubble growth rates and to the time that individual bubbles attached to the heater surface. Within the partial nucleate boiling region bubbles barely change in size and shape while sliding a long distance on the heater surface. With increasing heat flux, or reducing flow rate at constant heat flux, bubble growth rates increase significantly. Bubbles grow while sliding, detach from the heater, and subsequently collapse in the bulk fluid within a distance of 1-2 diameters parallel to the heater surface[5]. Hamid and Mehdi calculated the convective heat transfer coefficient and the wall temperature in a uniform heated tube with downward flow regarding the pressure drop along the tube. They investigated in this study two- phase flow pressure drop and two - phase properties such as void friction[6]. Bang and Kim studied experimentally the effect of pressure on the flow boiling of water in mini channels. The range of pressure was 2-16 bars in the experiments. The experimental apparatus consisted mainly of the $1.73 \mathrm{~mm}$ inner diameter round tube test section, gear pump, pre-heater, pressurize, pre evaporator, and condenser. He used the pre-evaporator for varying the vapor quality entering the test section. The pressurize control the desired system pressure. The test tube is made of 316 stainless steel and the test tube and the pre-evaporator tube were heated by DC electric current through the tubes. The measured flow boiling heat transfer coefficients were in the range of 10,000 $35,000 \mathrm{~W} / \mathrm{m}^{2} . \mathrm{K}$ and showed the general convection dominant trend in terms of vapor quality. The data also indicates that the pressure does not alter the heat transfer coefficient significantly[7]. Xiao Hu, Guiping, Yan Cai and Dongsheng, studied by Using FC-72 as the coolant, a closed- loop twophase mini channel heat sink driven by a micro-gear pump was developed in this work. The cooling system was made of oxygen-free copper containing 14 parallel channels of the dimension of $0.8 \mathrm{~mm}(\mathrm{~W}) * 2 \mathrm{~mm}(\mathrm{D}) * 20 \mathrm{~mm}(\mathrm{~L})$ [8].

\section{THEORETICAL ANALYSI}

Flowing water in a vertical annulus subjected to transient forced convection effect in radial direction is presented for modeling. A one- dimensional model can be used to describe the transient forced convection heat transfer in vertical annuals, with inner radius $r_{\mathrm{I}}$ and outer radius $r_{0}$ which has a configuration shown in figure (2). Water flow direction is assumed to be in the upward direction according to the experimental setup. The following assumptions are used in the modeling:

- Incompressible fluid.

- One dimensional in (z-axis) flow. There is only one non zero velocity component, namely that in the direction of flow, $v_{\mathrm{z}}$ thus, $\mathrm{v}_{\mathrm{r}}=\mathrm{v}_{\mathrm{g}}=0$.
- The axial velocity is independent of the angular location; that is, $\frac{\partial v_{z}}{\partial \theta} 0$.

- Simultaneously developing hydrodynamic.

- No internal heat generation and heat dissipation.

- Neglecting viscous dissipation.

- The flow during steady state condition is single phase as water bulk temperature does not exceed the saturation temperature along the cooling channel, $\mathrm{x}=0$.

The two phase flow and heat transfer during transient case at the upper part of the test section where water quality, $x>0$ is based on homogeneous model.

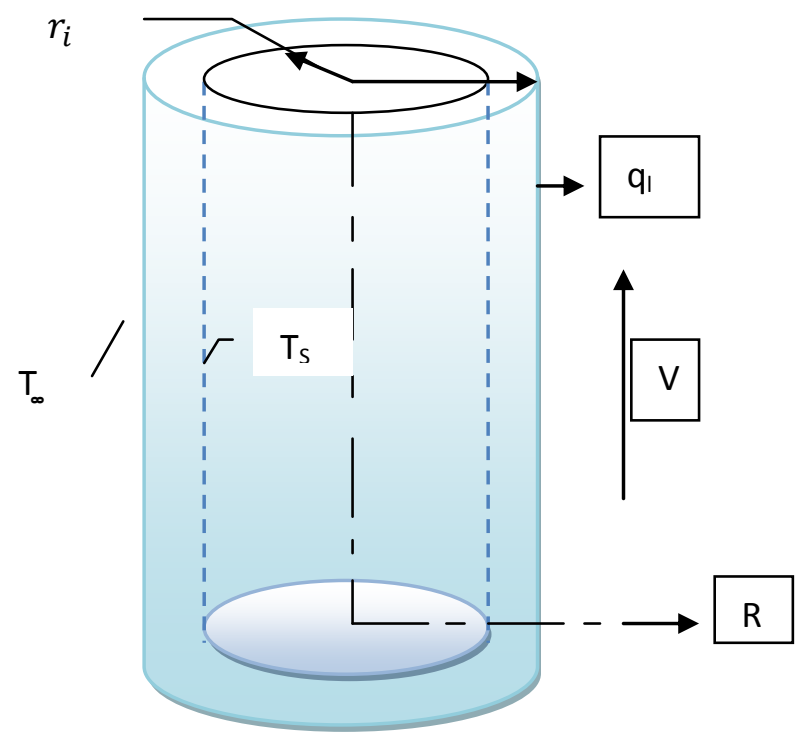

Fig (2): Axial annular geometry

\subsection{Formulas Used for Prediction Measured Parameters during Steady State Condition} To analyze the heat transfer process by forced convection from the heat source surface to the water flowing along it through annular section adjacent to the heat source surface simplified steps were used by conducting mass and heat balance at specified cross sectional area in the channel. The heat transfer coefficient is one of the affective parameters that should be estimated using the proper equations, Calculation procedure is conducted as follows:

- The total input power supplied to the wall can be calculated as;

$$
\mathrm{q}_{\mathrm{t}}=\mathrm{V} \approx \mathrm{I}
$$

- The heat loss ( $\left.q_{1}\right)$ from the annular channel to the surrounding can be found from the following relation:

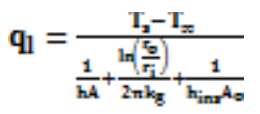

- The outer heat transfer coefficient of insulated cylinder $\left(\mathbf{h}_{\mathrm{Ins}}\right)$ is found using the following equation, (Harlan and Bengtson, [9]. The correlation for Nu adopted for laminar flow at $\left(\mathbf{R a} \leq 10^{y}\right)$ is: 


$$
\begin{aligned}
& \mathrm{Nu}=0.68+\frac{0.67 \cdot \mathrm{Ra}^{25}}{\left[1+\left(\frac{492}{\mathrm{Pr}}\right) \cdot 915\right]^{49}} \\
& \mathrm{Gr}=\mathrm{g} \beta \mathrm{L}^{3} \Delta \mathrm{T} / \mathrm{\theta}^{2} \\
& \operatorname{Pr}=\left(\frac{\mu c_{b}}{k}\right)=0 \\
& \mathbf{R a}=\mathbf{G r} * \mathbf{P r} \\
& \mathbf{h}_{\mathrm{fns}}=\left(\mathrm{Nu} * \mathbf{k}_{\mathrm{ma}}\right) /(\mathrm{z})
\end{aligned}
$$

- Heat transferred to the flowing water by convection is calculated by the following relation;

$$
\mathrm{q}_{\mathrm{c}}=\mathrm{q}_{\mathrm{t}}-\mathrm{q}_{\mathrm{l}}
$$

- Convective heat flux is calculated by using the following relation;

$$
\begin{aligned}
& q^{m}=q_{c} / A_{s} \\
& A_{s}=\pi d_{1} L
\end{aligned}
$$

- The cross section area of annular tubes, in which the cooling water flowing inside it could be calculated as follows:

$$
A_{\mathrm{f}}=\frac{\pi}{4}\left(d_{0}^{2}-d_{1}^{2}\right)
$$

- The average velocity of water could be determined as follows:

$$
\mathrm{V}=\mathrm{Q} / \mathrm{A}_{\mathrm{f}}
$$

The input parameters related to the total power of the heat source, hydraulic diameter, water volumetric flow rate, channel geometry and inlet water temperature are based on the experimental data that are used during the experimental part of the study. The target from theoretical study is to ensure certain model that predicts the measured parameters during transient condition initiated by pressure step reduction. These parameters include water and surface temperatures response to such disturbance and the elapsed time required to gain the steady state condition again. The results obtained from the experimental and theoretical results are compared with each other

\subsection{Bulk water temperature}

To determine the bulk water temperature at the six points and compare them with the six thermocouple read out fixed along heater tube wall during study state condition, the following calculations are conducted;

$$
\mathrm{T}_{\mathrm{w} 1+1, s t}=\mathrm{T}_{\mathrm{w} 1, s \mathrm{t}}+\left(\frac{\mathrm{q}^{\mathrm{m} \pi \mathrm{d}_{i} z}}{\mathrm{~m} \cdot \mathrm{cp}}\right)
$$

\subsection{Local Heat Transfer Coefficient}

In order to investigate if the flow in the test section is fully developed or developing flow, it is necessary to estimate the thermal entrance length, $\mathbf{z}_{\text {et }}$ as given by the following expression; (Ebadian and Dong, 2006)[10].

$$
T_{f(i+1)}=\frac{T_{x[+2]}+I W_{[1+2]}(t)}{2}
$$

$$
\text { Where }\left(\mathrm{p}_{v} \mathrm{C}_{\mathrm{p}} \mathrm{Pr}_{v} \mu\right)=\mathrm{f}\left(\mathrm{T}_{\mathrm{f}(\mathrm{i}+1)}\right)
$$

The following equation is used to calculate the heat transfer coefficient as shown below, (EL-Wakil, 1962)[11].

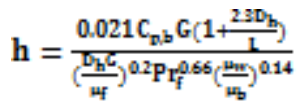

$$
\begin{aligned}
& \mathrm{G}=\frac{\text { fluid massflow rate } \mathrm{kg} / \mathrm{sec}}{\text { cross section area of channel, } \mathrm{m}^{2}}=\frac{\dot{\mathrm{m}}}{\mathrm{A}_{\mathrm{f}}} \\
& D_{h}=4 \frac{(\pi / 4)^{2}+\left(d_{a}^{2}-d_{j}^{2}\right)}{\pi\left(d_{a}-d_{1}\right)}=\left(d_{0}-d_{1}\right)
\end{aligned}
$$

The previous equations are based for calculation local heat transfer coefficient, $\mathbf{h}$ for forced convection using sub-cooled liquid.

\subsection{Surface Temperature of Electrical Heater (heat source)}

Clad surface temperature of heat source is calculated from the following equation:

$$
\mathrm{T}_{\mathrm{s}}=\mathrm{T}_{\mathrm{w}[(1+1)]}(\mathrm{t})+\frac{\mathrm{q}^{\mathrm{T}}}{\mathrm{h}}
$$

\subsection{Sub-cooled Boiling Temperature and Safety Factor Estimation}

Sub-cooled nucleate boiling of the coolant starts when the heat source surface temperature reach to the boiling temperature at that position; $\mathbf{T}_{\mathbf{w} .}$ The following correlation is used for $\mathbf{T}_{w}$ estimation; (Ezzat and Taki, 1988)[12].

$$
\begin{aligned}
& T_{W}=T_{\text {sat }}+2.03 * q^{u .3 b} * P^{-u .2 s} \\
& \mathbf{P}=\mathbf{P}_{\mathrm{i}}-\rho \operatorname{g~z}-\left(\mathbf{f} \frac{\mathrm{Z}}{\mathrm{D}_{\mathrm{h}}}\right) \cdot\left(\frac{\mathrm{V}^{2}}{2 \mathrm{~g}}\right)
\end{aligned}
$$

To avoid sub-cooled nucleate boiling at clad surface, the maximum clad temperature at the hot spot shall be lower than boiling temperature. A safety factor $(\mathrm{K})$ given by the following equation. $\mathbf{K}$ used to estimate this temperature; (Ezzat and Taki, 1988).

$$
\mathrm{K}=\left(\mathrm{T}_{\mathrm{B}}-\mathrm{T}_{\mathrm{fn}}\right) /\left(\mathrm{T}_{\mathrm{s}}-\mathrm{T}_{\mathrm{fn}}\right)
$$

To find out heat transfer coefficients after initiating of nucleate boiling on heat source surface it is necessary to add another part to the equation used for sub-cooled liquid, as nucleate boiling will enhance heat transfer mechanism due to turbulence effect of vapor nucleation. The following equation is used for calculating flow boiling heat transfer by (Chen 1963)[12].

$$
\mathbf{h}_{\mathrm{B}}=\mathbf{h}+\mathbf{h}_{\mathrm{NB}}
$$

Where

$$
\mathrm{h}_{\mathrm{NB}}=\frac{0.00122 * S\left(\Delta \mathrm{T}_{\text {gat }}\right)^{0.24}\left(\Delta \mathrm{p}_{\text {sat }}\right)^{0.75} \mathrm{C}_{\mathrm{pl}}^{0.45} \mathrm{k}_{1}^{0.79} \mathrm{Pl}^{0.49}}{\sigma^{0.5 \lambda^{0.24} \mu_{\eta}^{0.29} \mathrm{P}_{g}^{0.24}}}
$$




\subsection{Derivation of Temperature Response to Pressure Reduction Transient According to Step Disturbance Function}

The derivation of bulk water and surface temperature to pressure step reduction is based on the flow pattern and water quality along the channel. Could be derived from the following heat balance and as shown in figure (3):

$T_{\mathrm{z}}=\mathrm{T}_{\mathrm{w1}}+\frac{\mathrm{q}^{\mathrm{n}} \pi \mathrm{dz} \mathrm{d}}{2 \mathrm{~m} \mathrm{C}_{\mathrm{p}}}$

$\mathrm{T}_{\mathrm{z}}=\frac{1}{2}\left[\mathrm{~T}_{\mathrm{w}(1+1)}+\mathrm{T}_{\mathrm{w} \mathrm{I}}\right]$

$\mathrm{T}_{\mathrm{w}(1+1)}=2 \mathrm{~T}_{\mathrm{z}}-\mathrm{T}_{\mathrm{w} 1}$

Then,

$\mathrm{T}_{\mathrm{w}(1+1)}=\mathrm{T}_{\mathrm{f}(1+1)}+\mathrm{x}_{1+1} * \mathrm{~T}_{\mathrm{fg}(1+1)}$

$2 \mathrm{~T}_{\mathrm{z}}-\mathrm{T}_{\mathrm{w} 1}=\mathrm{T}_{\mathrm{f}(1+1)}+\mathrm{x}_{1+1} * \mathrm{~T}_{\mathrm{fg}(1+1)}$

It is assumed that (i) is the point where local temperature $\left[T_{\mathrm{w} 1}=T_{\mathrm{szt}}\right]$ at that point $\left[\mathrm{T}_{\mathrm{w} 1}=\mathrm{T}_{\mathrm{f}(\mathrm{T})}\right]$.

$\frac{1}{2}\left[T_{w 1}+T_{f(1+1)}+x_{1+1} * T_{f g(1+1]}\right]=T_{w 1}+\frac{q^{w} \pi d z d}{2 \dot{m} C_{p}}$

$\mathrm{x}_{1+1}=\frac{1}{\mathrm{Tw}(\mathrm{i}+1\}}\left[\mathrm{T}_{\mathrm{w} 1}+\frac{\mathrm{q}^{\mathrm{n}} \pi \mathrm{d} d \mathrm{~d}}{2 \mathrm{~m} \mathrm{C}_{\mathrm{v}}}+\mathrm{T}_{\mathrm{f}(1+1)}\right]$

Where:

$$
\begin{aligned}
& \mathrm{T}_{\mathrm{f}(\mathrm{I}) \dot{ }} \mathrm{T}_{\mathrm{fg}(1)}=f\left(\mathbf{P}_{1}\right) \\
& \mathrm{T}_{\mathrm{f}(1+1) \rho} \mathrm{T}_{\mathrm{fg}(1+1)}=f\left(\mathbf{P}_{1+1}\right)
\end{aligned}
$$

Now, we will use $\left(\mathbf{x}_{1+1}\right)$ to calculate the temperature and pressure at $(i+1)$ using the same steady state equation taking into account the effect of two phase water quality $\mathbf{x}_{1+1}$

$P_{1+1}=P_{1}-\left(f \frac{Z}{D_{h}}\right) \cdot\left(\frac{V^{2}}{2 g}\right)-g d z\left(\rho_{f(1+1)}+x_{1+1} * \rho_{f g(1+1)}\right) * d t$

First we assume $P_{\mathbf{i}+1}$ to find out $\mathbf{x}_{\mathbf{i}+\mathbf{1}}$ then we use the new value of $\mathrm{P}_{\mathrm{i}+1}$ to investigate the new value of $\mathbf{x}_{\mathbf{i}+\mathbf{1}}$. After certain iteration and when the value of $\mathrm{P}_{\mathrm{i}+1}$ stabilize we base the final value of $\mathbf{x}_{\mathbf{i}+\mathbf{1}}$ to calculate $\mathrm{T}_{\mathbf{w}(\mathbf{i}+\mathbf{1})}$ as shown below:

$T_{1+1}=T_{1}+\frac{q^{\prime \prime} \pi d z d}{\left(1-x_{i+1}\right) \dot{m} C_{p}}$

At $\mathrm{i}=0 \quad \mathbf{P}_{\mathbf{1}}=\mathbf{P}_{\mathbf{I}} \quad$ which the steady state pressure $=1.3$ bar.

During transient course at $\mathrm{t}>0 \quad \mathrm{p}_{\mathrm{i}}=1.0$ bar.

Water velocity inside the channel will be used to find the position of the affected position $\mathrm{x}_{1}$ at which $\mathbf{T}>\mathbf{T}_{\mathrm{sat}}$ after each time interval.

i.e: at $\mathrm{t}=\mathrm{t} 1$

All the positions which are less than $\mathrm{x} 1, \mathrm{x} 2, \ldots$. etc. till $\mathrm{x}=\mathrm{L}$ ,length of heat source, will be using temperature distribution based on inlet pressure of 1.3 bar, i.e steady state equation. While positions which are above $\mathrm{x} 1, \mathrm{x} 2, \ldots$. etc. will use temperature distribution based on inlet pressure equal to 1.0 bar, i.e transient equation.

Accordingly the temperature distribution along the heat source surface will be calculated based on $\left(\mathrm{T}_{\mathrm{w}}\right)$ found from the above equations. Clad surface temperature, $\left(\mathrm{T}_{\mathrm{S}}\right)$ will be calculated based on the following equation:

$$
T_{S[(1)}=T_{W(1)}+\frac{q^{I T}}{h_{i}} .
$$

Note: that $\mathbf{T}_{\mathbf{w}(1+1)}$ will be based on following equation which is used for steady state condition when the position (i) falls below $\mathrm{T}_{\text {sat }}$ position.

$T_{\mathrm{w}(1+1)}=T_{\mathrm{w} 1}+\frac{\mathrm{q}^{\mathrm{tI}} \pi \mathrm{dzd}}{\mathrm{m} \mathrm{C}_{\mathrm{p}}}$

The following equation is used to find out $\mathbf{T}_{\mathrm{w}(1+1)}$ when (i) falls above $\mathrm{T}_{\text {sat }}$ position.

$T_{\mathrm{w}(1+1)}=T_{\mathrm{w} 1}+\frac{\mathbf{q}^{\mathrm{ut}} \pi \mathrm{dz} \mathbf{d}}{\left(1-\mathrm{x}_{1+1}\right) \dot{\mathbf{m}_{\mathrm{p}}}}$

When the position reaches to the film boiling region, the heat transfer coefficient $\left(\mathbf{h}_{f}\right)$ is then given by:

$\mathbf{h}_{f}=\frac{\pi}{24} \mathbf{h}_{f g} \rho_{v}\left[\frac{\sigma g\left(p_{I}-p_{v}\right)}{p_{v}^{2}}\right]^{\frac{1}{4}}\left(1+\frac{p_{v}}{p_{I}}\right)^{\frac{1}{2}}$

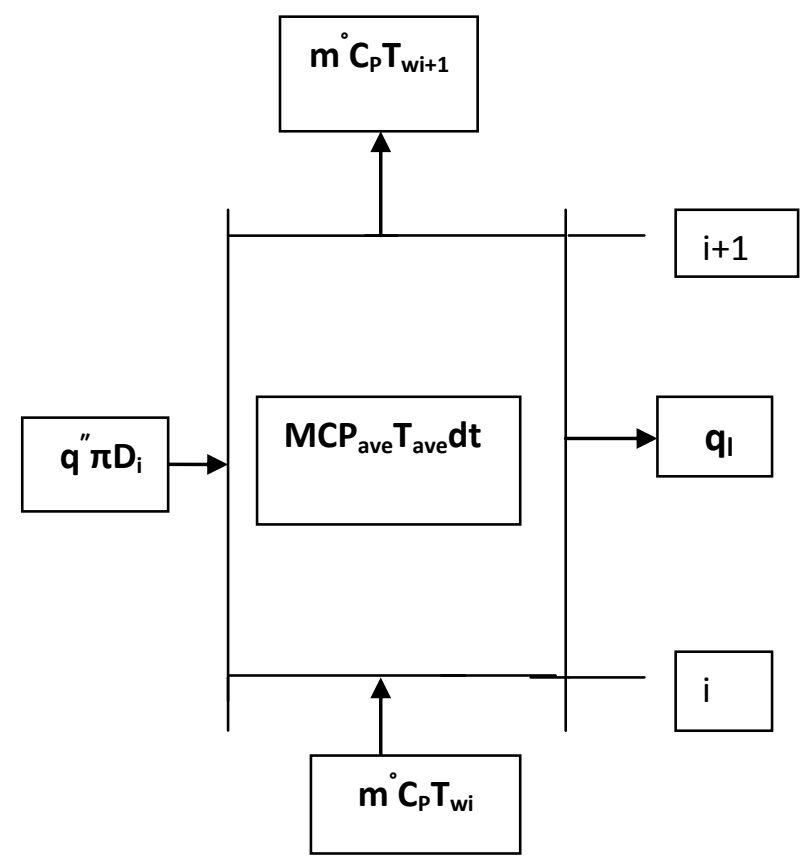

Fig (3): Heat balance mass transfer

\section{EXPERIMENTAL WORK}

The experimental system consists of $0.7 \mathrm{~m}$ vertical mounted glass test section pipe linked to water circulation system. The water loses part of its static head as it moves up due to frictional pressure drop along the test section. Accordingly the local pressure along the channel is function of its pressure at the channel inlet, water velocity and water density which is in turn is function of the local 
water quality. Accordingly film boiling will be ensured somewhere inside the test section where the water local temperature reaches its saturation temperature at that position. The inlet pressure reduction versus time is simulated by three disturbance functions: step change, ramp change and sinusoidal change. According to the design criteria of the test rig the range of the pressure reduction in the test section inlet is limited to (1.3 to 1.0) bar. Proper cylindrical shape heat source is fabricated to ensure constant heat flux used to heat up the upward flowing water in the vertical annulus that surrounds it. The heat source consists of a nickel-chrome wire, wounded as (U) shape coil inside solid stainless steel cylinder and the stainless steel tube to ensure constant heat flux. The length of the heater is $(70 \mathrm{~cm})$, while it's heating active length is $(66 \mathrm{~cm})$, the diameter is $(2 \mathrm{~cm})$, the maximum total power is $(2500 \mathrm{~W})$, resistance of heat source $(19.2 \Omega)$ and the maximum applied voltage (220-240) Volts. The outer tube of the circular annulus is made of Perspex glass to minimize the heat lost to the surrounding air due to its low thermal conductivity in addition to its transparency to enable visualization the flow patterns during water phase change. The cylindrical channel thickness is $(1 \mathrm{~cm})$, its length is $(70 \mathrm{~cm})$, with inner diameter equals $(2.5 \mathrm{~cm})$ and outer diameter equals $(4.5 \mathrm{~cm})$. Proper flanges made from Teflon are fitted in the both ends of the cylindrical channel to ensure the gap between the two concentric cylinders equal to $0.25 \mathrm{~cm}$. The temperature of the outside surface of the inner cylinder heat source is measured by using six asbestos sheath alumel - chromel (type K) thermocouples installed in six positions $(6.5,19.5,32.5$, $45.5,58.5$ and 66) $\mathrm{cm}$ from the entrance of the heat source active length. Circular holes of $(\mathrm{d}=2 \mathrm{~mm})$ are drilled in the surface of the Perspex glass cylinder which are used for thermocouple penetration. They are installed in equal space distances at six positions while the bulk water temperature was measured by using three thermocouples which are fixed in distances $(19.5,45.5$ and 65$) \mathrm{cm}$ from the channel entrance, while two thermocouples are installed inside the channel to measure water temperature in the inlet and the outlet of the channel. To determine the heat lost from the channel to the surrounding, three thermocouples are fixed in the lengths $(19.5,45.5$ and 65$)$ $\mathrm{cm}$ of the channel for the purpose of estimating the temperature at the outer surface of the Perspex glass and then calculating the heat lost to the surrounding air by the following equation;

$q_{l}=h_{\text {ins }}\left(T_{s}-T_{\infty \infty}\right)$

The supplied water to the annular test section is heated up to the inlet water temperature in a rectangular cross section tank. The tank is shown in plates (1) and figure (4).

'The conducted experiments are based on the following input parameters, water temperature at the entrance of the channel range $\left(76^{\circ} \mathrm{C}-80^{\circ} \mathrm{C}\right)$. Water flow rate is fixed at $1.41 / \mathrm{m}$. Sharp pressure fluctuation at any of these points predicts the transition of boiling configuration from nucleate boiling to film boiling at distance located upper from the pressure fluctuation point. Water flow pressure at distances $(6.5,32.5$ and 65$) \mathrm{cm}$ from the heated wall inlet is measured by the water manometer during the pressure reduction transient. Temperature Response to Pressure reduction are conducted for 3 types of disturbance functions: step, ramp and sinusoidal.

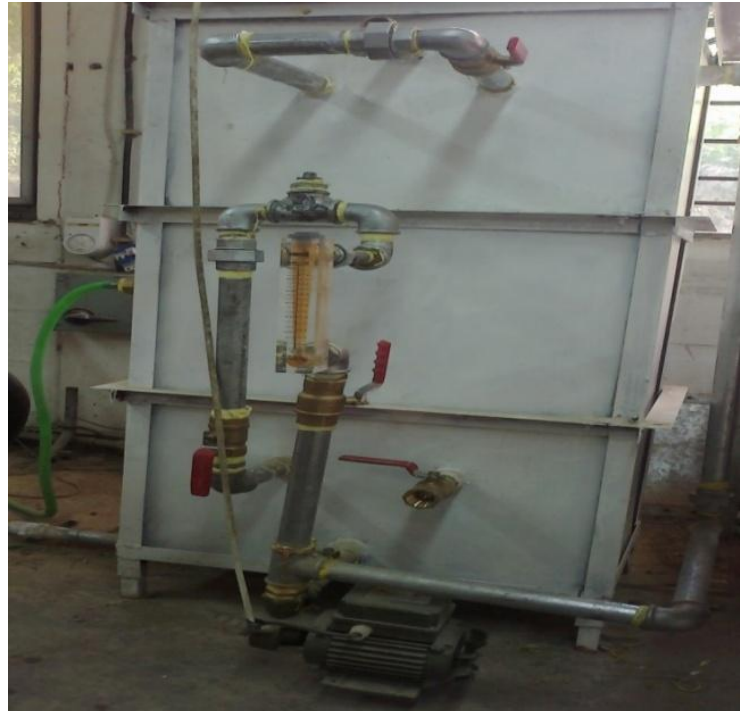

Plate (1.a): Test rig used for conducting experimental tests- front View.

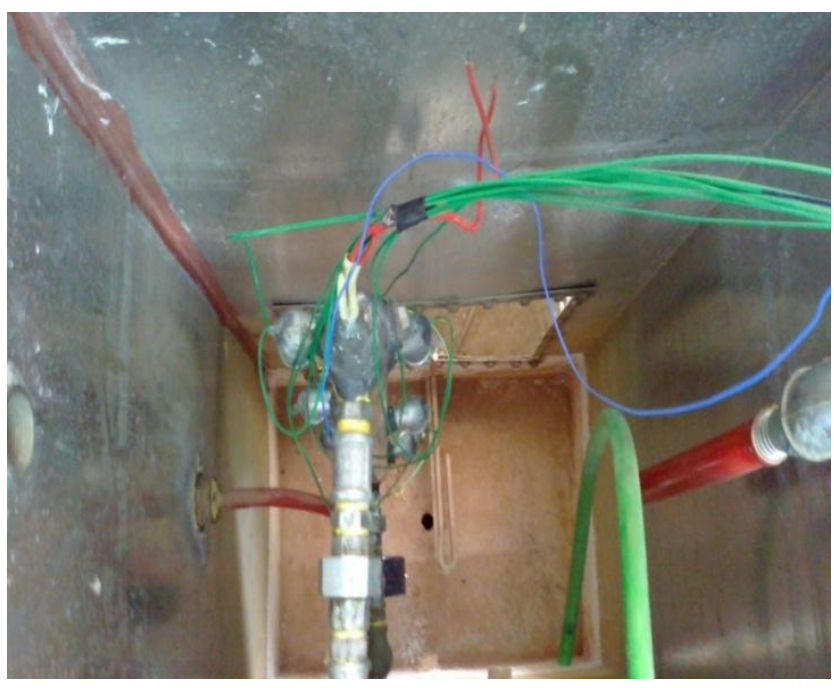

Plate (2.b): Top view of the water heating and circulation tank 


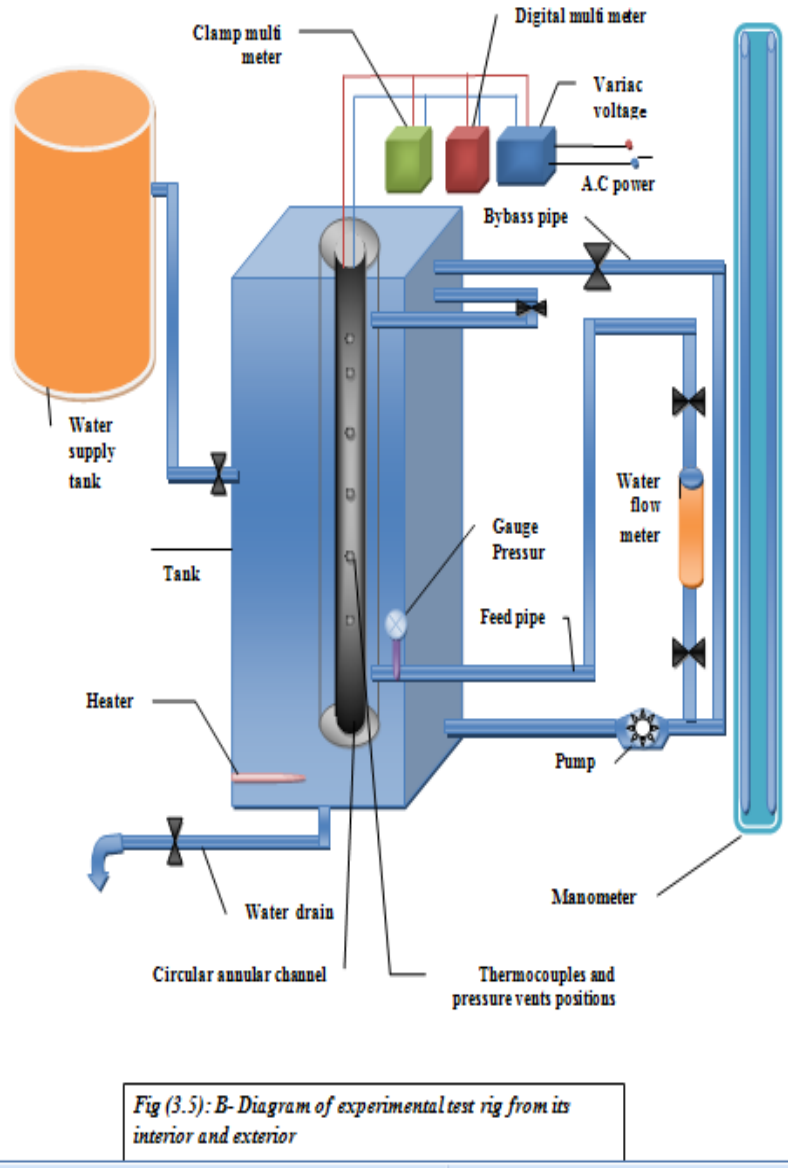

\section{Fig (4): Diagram of experimental test rig from its interior} and exterior

\section{RESULT AND DISCUSSION}

Generally, the variation of the temperature along the heat source clad surface may be affected by many variables such as the input heat flux, water inlet temperature, water velocity inside the channel, gap between concentric cylinders and the distances of the test section at which the clad temperature is measured or calculated. Figure (5) shows the effect of pressure step reduction transient on the heat source clad surface temperature at the end of the electrical heat source, $(65 \mathrm{~cm})$ and $\left(\Delta \mathbf{T I} \mathbf{s u b} .=24^{\circ} \mathrm{C}\right)$. The figure shows that the maximum surface temperature measured at the end of the heat source starts to decreases after initiating the transient due to the effect of water bulk temperature decrease affected by the water phase change which uses water latent heat for evaporation during its flow at the part of channel where the local pressure is below the saturation pressure. Figure (6) shows the effect of pressure step reduction transient on the heat source clad surface temperature at the end of the electrical heat source, $(65 \mathrm{~cm})$ and $\left(\Delta \mathbf{T I}\right.$ sub. $\left.=20^{\circ} \mathrm{C}\right)$. The figure shows the same behavior of figure (5). The figure also illustrate that the difference between the experimental and theoretical approach is acceptable. Figure (7) represents the curves plotted for pressure step reduction transient conditions at $\Delta \mathbf{T I}$ sub. equals $\left(30^{\circ} \mathrm{C}, 24^{\circ} \mathrm{C}\right.$ and $\left.20^{\circ} \mathrm{C}\right)$ respectively. It is clear that the elapsed time required for clad surface temperature to reach their steady state values is proportional to the water sub-cooled degree at the channel inlet. The figure illustrates also the behavior of clad temperature based on experimental results. It is clear that water sub-cooled temperature at channel inlet slightly affect the clad temperature after the end of the transient course. Figure (8) shows the effect of pressure ramp reduction transient on the heat source clad surface temperature at the end of the electrical heat source, $(65 \mathrm{~cm})$ and $\left(\Delta \mathrm{TI}\right.$ sub.$\left.=24^{\circ} \mathrm{C}\right)$. It shows the pressure ramp reduction effect based on 30 seconds period. The figure shows that the measured surface temperature at the end of the heat source decreases versus pressure reduction due to the effect of water bulk temperature decrease affected by the water phase change which uses water latent heat for evaporation during its flow at the part of channel where the local pressure is below the saturation pressure. Figure (9) shows the effect of pressure reduction transient according to sinusoidal disturbance function on the heat source clad surface temperature at the end of the electrical heat source, $(65 \mathrm{~cm})$ and $\left(\Delta \mathrm{TI}\right.$ sub. $\left.=24 \mathrm{C}^{\mathrm{O}}\right)$. Three transient periods are selected during these experiments $(30$ seconds, 60 seconds and 90 seconds) which represents pressure reduction period. Figure (9) shows the pressure reduction effect based on 30 seconds period. As discussed before that the surface temperature is directly proportional to the pressure reduction history and the values of these temperatures follow the same disturbance function shape without any time delay. This behavior is affected by water velocity in the channel and the period of the disturbance function. It is clear also that maximum difference between the clad surface temperature at this point before the transient course and within the whole disturbance cycle does not exceed $2.5^{\circ} \mathrm{C}$. Figure (10) shows the experimental and theoretical bulk water temperature versus elapsed time required to reach the steady state condition at the end of the heat source, $(65 \mathrm{~cm})$ and $\left(\Delta \mathrm{TI}\right.$ sub. $\left.=20^{\circ} \mathrm{C}\right)$. The figure shows that the maximum water temperature is measured at the end of the heat source then it begins to decrease due to the effect of water bulk temperature decrease affected by the water phase change which uses water latent heat for evaporation during its flow at the part of channel where the local pressure is below the saturation pressure. The figure illustrates also perfect compatibility between theoretical and experimental results. The experimental results related to the water bulk temperature versus the elapsed time required to reach these temperatures to their steady state values at the end of the heat source, $65 \mathrm{~cm}$ are plotted. Figure (11) represents the curves plotted for pressure step reduction transient conditions at $\mathbf{\Delta} \mathbf{T I}$ sub. equals $\left(30^{\circ} \mathrm{C}, 24^{\circ} \mathrm{C}\right.$ and $\left.20^{\circ} \mathrm{C}\right)$ respectively. It is clear that the elapsed time required for bulk water temperature to reach their steady state values is proportional to the water sub-cooled degree at the channel inlet. Table (1) shows the related parameters at (100\%) elapsed time of each $\Delta \mathbf{T I}$ sub. at the end of the heater, $(65 \mathrm{~cm})$. The effect of pressure reduction ramp change transient on the bulk water temperature at the end of the electrical heat source, $(65 \mathrm{~cm})$ related to water sub-cooled temperature $\left(\Delta \mathbf{T I}\right.$ sub. $\left.=\mathbf{2 4} \mathbf{C}^{\mathbf{0}}\right)$ plotted in figure $(12)$. Three transient periods are selected during these experiments (30 seconds, 60 seconds and 90 seconds) which represents pressure ramp reduction period. Figure (12) shows the pressure ramp reduction effect based on 30 seconds period. The figure shows that the measured water bulk temperature at the end of the heat source decreases versus pressure reduction due to water phase change which uses water latent heat for evaporation during its flow at the part of channel where the local pressure is below the saturation pressure. The figure illustrates that as the transient period increase the water bulk temperature graph posse flatter response. Another conclusion is investigated which prove that pressure reduction period do not affect water bulk temperature value at the end of the transient course, while the elapsed time required for water bulk temperature to reaches their steady state values is 
proportional to the pressure reduction period. Figure (13) shows the effect of pressure reduction transient according to sinusoidal disturbance function on the water bulk temperature at the end of the electrical heat source, $(65 \mathrm{~cm})$ and $(\Delta \mathrm{TI}$ sub. $=24^{\circ} \mathrm{C}$ ). Three transient periods are selected during these experiments (30 seconds, 60 seconds and 90 seconds) which represents pressure reduction period. Figure (13) shows the pressure reduction effect based on 30 seconds period. As discussed before that the water bulk temperature is directly proportional to the pressure reduction history and the values of these temperatures follow the same disturbance function shape. Another conclusion is reached that demonstrates water bulk temperature at the end of the transient is proportional to the transient period. Figure (14) shows the experimental and theoretical values of the heat transfer coefficient versus distance during steady state condition at $\left(\Delta \mathrm{TI}\right.$ sub. $\left.=20^{\circ} \mathrm{C}\right)$. The figure reveals that the heat transfer coefficient distribution along the heat source length after reaching the steady state condition keeps its linear proportionality with distance which ensures maximum heat transfer coefficient at the end of the heat source, $(65 \mathrm{~cm})$ due to the effect of average bulk water velocity increase along the channel affected by water density decease to ensure continuity provision. The figure shows agreeable conformity between the experimental and theoretical results. Figure (15) shows the experimental and theoretical heat transfer coefficient versus the elapsed time after reaching the steady state condition at the end of the heat source, $(65 \mathrm{~cm})$ during $\left(\Delta \mathrm{TI}\right.$ sub. $\left.=20^{\circ} \mathrm{C}\right)$ and pressure step reduction transient. The heat transfer coefficient at the end of the channel decreases with time during pressure reduction transient due to the effect of film boiling near the heat source surface at the that portion which reduces the ability of the two phase flow on heat transfer mechanism between the heat source surface and bulk water. The figure shows agreeable conformity between the experimental and theoretical results.

Table (1): the values of parameters $\left(t, T_{b}, T_{\text {im }}, q^{\prime}\right)$ in present study

\begin{tabular}{||c||c||c||c||c||}
\hline $\begin{array}{c}\Delta \text { TI sub. } \\
\left({ }^{\circ} \mathrm{C}\right)\end{array}$ & $\begin{array}{c}\text { Inlet Temp. } \\
\left({ }^{\circ} \mathrm{C}\right)\end{array}$ & $\begin{array}{c}\text { Max. heat } \\
\text { flux }\left(\mathrm{kW} / \mathrm{m}^{2}\right)\end{array}$ & $\begin{array}{c}\text { Time } \\
(\mathrm{s})\end{array}$ & $\begin{array}{c}\text { Exp. of } \mathrm{Tb} \\
\left({ }^{\circ} \mathrm{C}\right)\end{array}$ \\
\hline \hline 30 & 70 & 45.9 & 125 & 93 \\
\hline \hline 24 & 76 & 45.9 & 102 & 97.9 \\
\hline \hline 20 & $\mathbf{8 0}$ & 47.1 & 78 & 99.1 \\
\hline
\end{tabular}

\section{CONCLUSIONS}

The results of the experimental and theoretical investigation are mainly describes the thermal-hydraulic behavior of an electrical heat source cooled by forced convection of water flow in upward in a vertical annulus during pressure reduction transient conditions. As many other previous researches outputs and conclusions of such type of studies describes the safety margins of boiling crisis, necessary mitigating action required to be interfered by the engineering safety features systems, ESFS. The following conclusions can be made:

1- Pressure reduction studied by three types of disturbance functions (step change, ramp change and sinusoidal) showed that pressure reduction effect on the bulk water and heat source surface temperatures is more evident in step and ramp disturbance functions than that of pressure reduction according to sinusoidal disturbance function due to the continuous pressure recovery after each half period.
2- Heat transfer process improves versus pressure reduction transient due to the effect of nucleate boiling which depends on the nominal power rate, pressure decrease rate, coolant mass flow rate, channel geometry and sub-cooled degree of inlet water. The heat source surface temperature is affected by both the phase of the bulk water and its temperature, as the heat transfer between the surface and the bulk water is affected by the turbulence initiation due to the bubble formation on the surface which nominated by nucleate boiling and predicted by boiling safety factor as mentioned in previous chapters.

3- As the power source is constant heat flux, clad surface temperature reaches its maximum value at the end of the heat source, $(0.65 \mathrm{~m})$ while the flow pressure decreases in the upward direction due to the friction and head pressure loss which leads to initialization of the boiling crisis at that part of the channel.

4- Step change pressure reduction showed that water bulk temperature reaches to almost same temperature after the step pressure reduction nevertheless the water sub-cooled degree at the channel inlet, while the elapsed time required to reaches this steady state value is proportional to the water sub-cooled degree and the maximum elapsed time is $125 \mathrm{~s}$ for $30^{\circ} \mathrm{C}$ subcooled degree. It is concluded also that heat source surface temperature is inversely proportional to the water sub-cooled degree as it reaches its maximum value at $20^{\circ} \mathrm{C}$ water subcooled degree while the maximum time required to reach the steady state value again is $118 \mathrm{~s}$ at water sub-cooled of $30^{\circ} \mathrm{C}$.

6- Ramp pressure reduction transient showed that the elapsed time required for both water bulk temperature and heat source surface temperature to reach their steady state values after transient course is proportional to the transient period. This time is $158 \mathrm{~s}$ for bulk water temperature and $152 \mathrm{~s}$ for heat source surface temperature at transient period equal $90 \mathrm{~s}$. which means that any safety system response to such power transients are more effective when their temperature sensors are linked to surface clad rather than bulk water.

7- Sinusoidal pressure reduction transient proved that both water bulk temperature and heat source surface temperature follows same pressure reduction shape and period due to immediate pressure recovery that do not allow phase change in the flowing water.

8- The heat transfer enhancement due to the nucleate boiling and its poor characteristic due to the film boiling accompanied by CHF should be taken under consideration in any thermal design of power generation systems selecting proper boiling safety factor, $(\mathrm{K})$ for their thermal hydraulic design.

\section{NOMENCLATURE}

$\begin{array}{cl}A_{0} & \text { Surface area of channel } \\ A_{s} & \text { Surface area of heat source } \\ C_{p} & \text { Specific heat of constant pressure } \\ d_{i} & \text { Inner diameter of heat source } \\ d_{o} & \text { Outer diameter of channel } \\ D_{h} & \text { Hydraulic diameter }=\left(D_{0}-D_{i}\right) \\ f & \text { Friction factor }(f=64 / R e) \\ g & \text { Gravity acceleration }\end{array}$


G

Mass velocity of water

$\mathrm{Gr}$

Grashof number

$\mathrm{h}$

Heat transfer coefficient

I

Current

$\mathrm{k}_{\mathrm{g}}$

Thermal conductivity of the insulated channel

K Boiling safety factor

L Length of heat source

$\mathrm{m}^{\circ}$

Mass flow rate of water

M

Mass of water

$\mathrm{P}$

Pressure

Inlet pressure at the top of the channel

pr

Prandtl number

qc

ql

qt

$q^{\pi}$

$\mathrm{Ra}$

Convective heat to the water

Heat lost to the surrounding air

Total heat power

Heat flux

Rayligh number

$\mathrm{r}_{\mathrm{i}}$

Inner radius of the insulated channel

$\mathrm{r}_{0}$

Outer radius of the insulated channel

Re Reynolds number

Q Flow rate of water

$\mathrm{t}$ Time

T Temperature

v Axial velocity

V Voltage

$\mathrm{z} \quad$ Axial distance along heat source

zet Thermal entrance length

\subsection{Greek letters}

$\beta \quad$ Coefficient of volume expansion

$\vartheta \quad$ Kinematic viscosity

$\rho \quad$ Density

\subsection{Subscript}

$\begin{array}{ll}\infty & \text { Surrounding air around channel } \\ \text { ave } & \text { Average } \\ \text { b } & \text { Bulk } \\ \text { in } & \text { Inlet water } \\ \text { ins } & \text { Insulator } \\ \text { out } & \text { outlet water } \\ \text { sat. } & \text { Saturated } \\ \text { st } & \text { Steady state condition } \\ \text { the.con } & \text { Theoretical conduction heat transfer }\end{array}$

\section{ACKNOELEDGMENTS}

Thanks for God for his entire blessing during the pursuit of my academic and career goals. I would like to express my sincere thanks, deep gratitude and high appreciation to my supervisor for his kind patronage, excellent scientific advice and motivation support throughout the steps of this work. My special thanks to all my colleagues and the staff of Mechanical Engineering Department of the University of Baghdad. My deep gratitude is towards my mother, my brothers and my wife for their incessant prayers, more support, guidance, encouragement and patience during my studies. They are the source of power, inspiration and confidence in me.

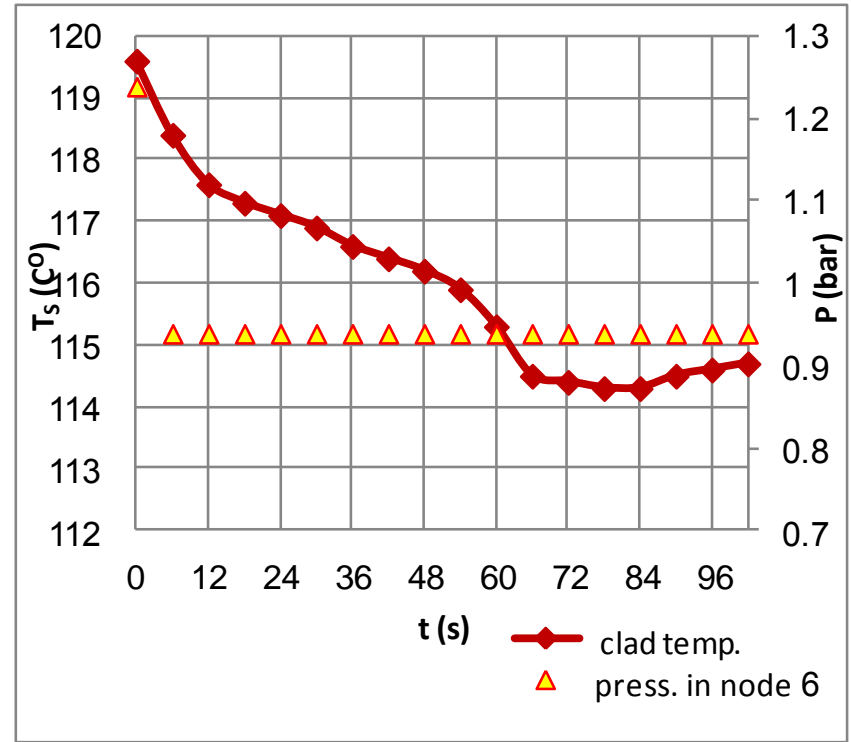

Fig (5): Experimental clad surface temperature versus time at the end of the heat source, $(65 \mathrm{~cm})$ during pressure step reduction, $\left(\Delta T I\right.$ sub. $=24^{\circ} \mathrm{C} ; q^{\prime \prime}=45900$ watt $/ \mathrm{m}^{2} ; \mathrm{V}=$ $0.121 \mathrm{~m} / \mathrm{s}$ ).

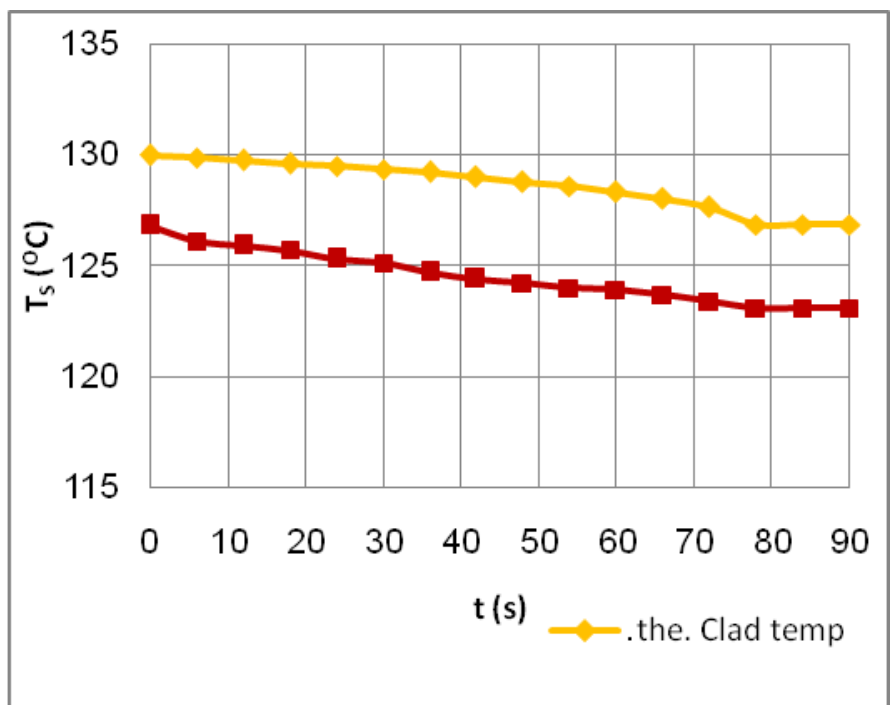

Fig (6): Theoretical and experimental clad surface temperature versus time at the end of the heat source, $(65 \mathrm{~cm})$ during pressure step reduction, $\left(\Delta \mathrm{TI}\right.$ sub. $=20^{\circ} \mathrm{C}$; $q=47100$ watt $\left./ \mathrm{m}^{2} ; \mathrm{V}=0.121 \mathrm{~m} / \mathrm{s}\right)$. 


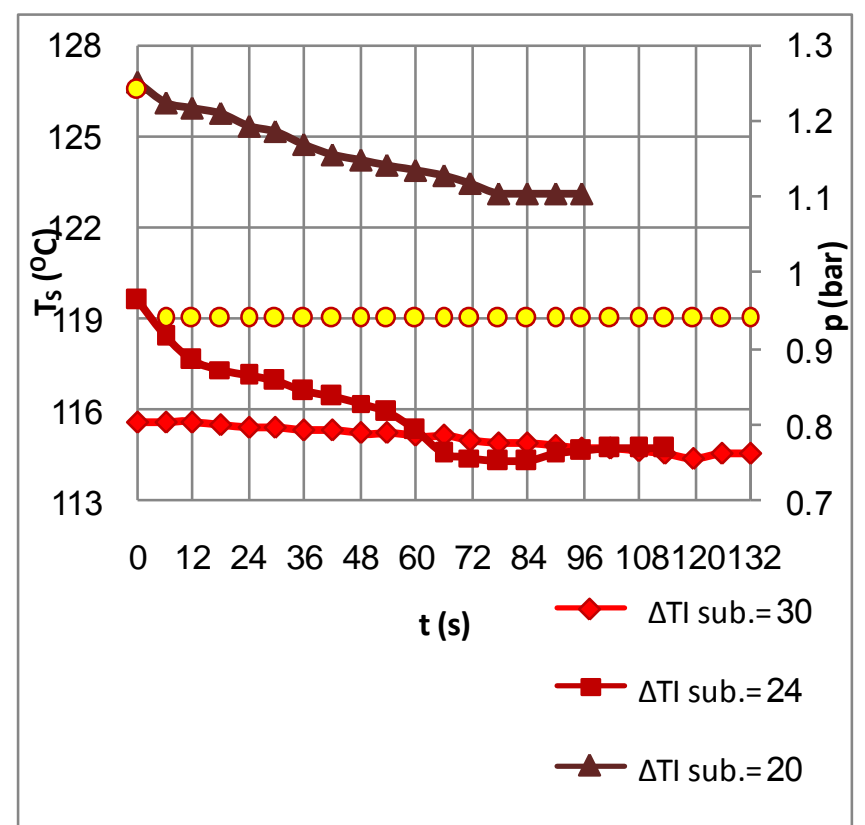

Fig (7): Experimental clad surface temperature versus time at the end of the heat source, $(65 \mathrm{~cm})$ during pressure step reduction, $\left(\Delta \mathrm{TI}\right.$ sub. $=30^{\circ} \mathrm{C}, 24^{\circ} \mathrm{C}$ and $\left.20^{\circ} \mathrm{C}\right)$.

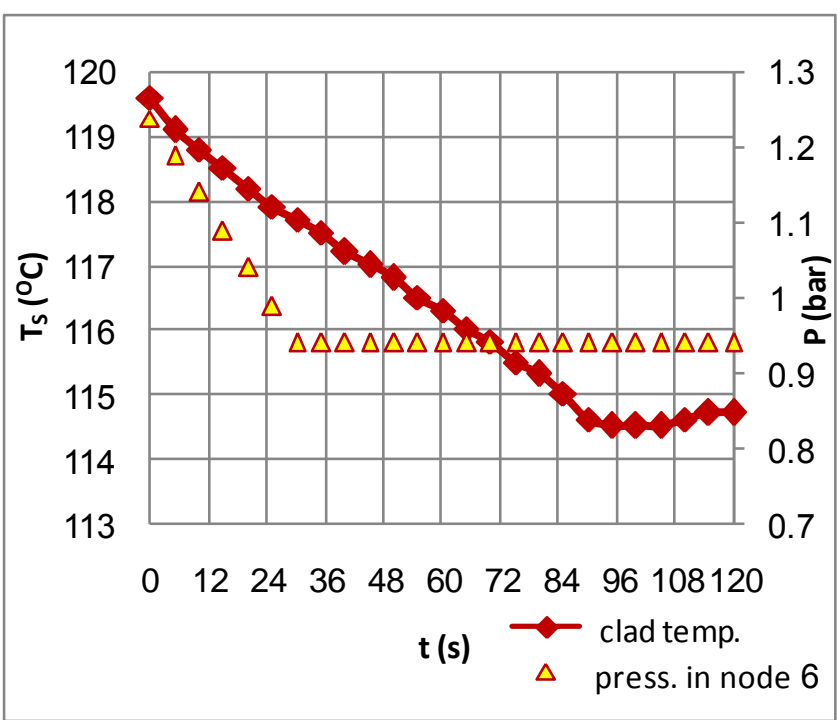

Fig (8): Experimental clad surface temperature versus time at the end of the heat source, $(65 \mathrm{~cm})$ during pressure ramp reduction $($ period $30 \mathrm{~s}),\left(\Delta \mathrm{TI}\right.$ sub. $=240 \mathrm{C} ; q^{\prime \prime}=45900$ watt $/ \mathrm{m} 2 ; \mathrm{V}=0.121 \mathrm{~m} / \mathrm{s})$.

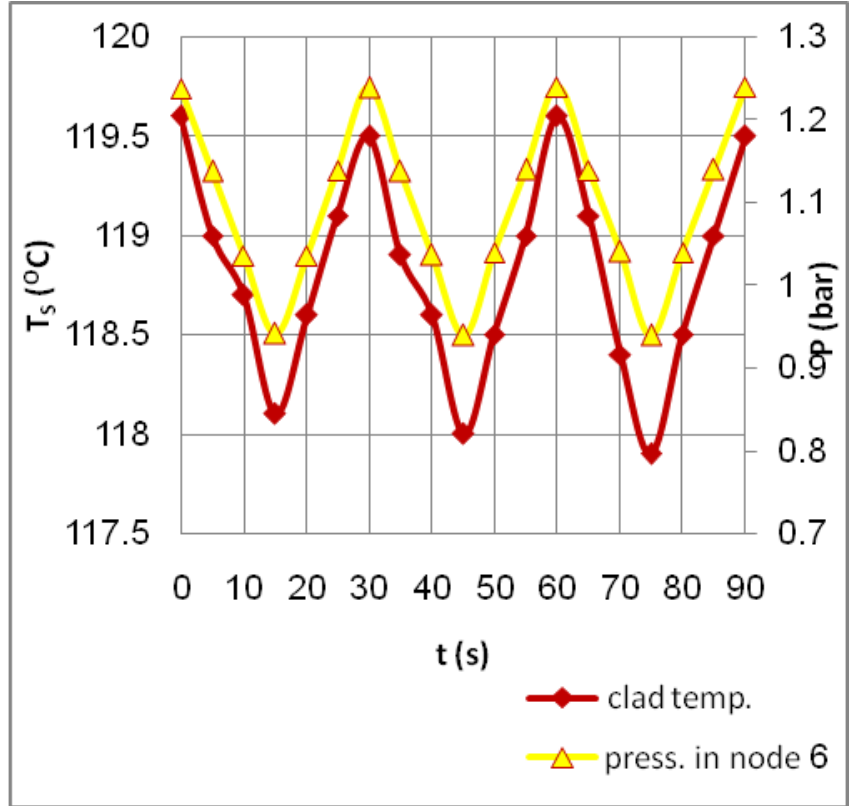

Fig (9): Experimental clad surface temperature versus time at the end of the heat source, $(65 \mathrm{~cm})$ during pressure sinusoidal change $($ period $30 \mathrm{~s}),\left(\Delta \mathrm{TI}\right.$ sub. $=24^{\circ} \mathrm{C} ; \mathrm{q}^{\prime \prime}=45900$ $\left.\mathrm{W} / \mathrm{m}^{2} ; \mathrm{V}=0.121 \mathrm{~m} / \mathrm{s}\right)$.

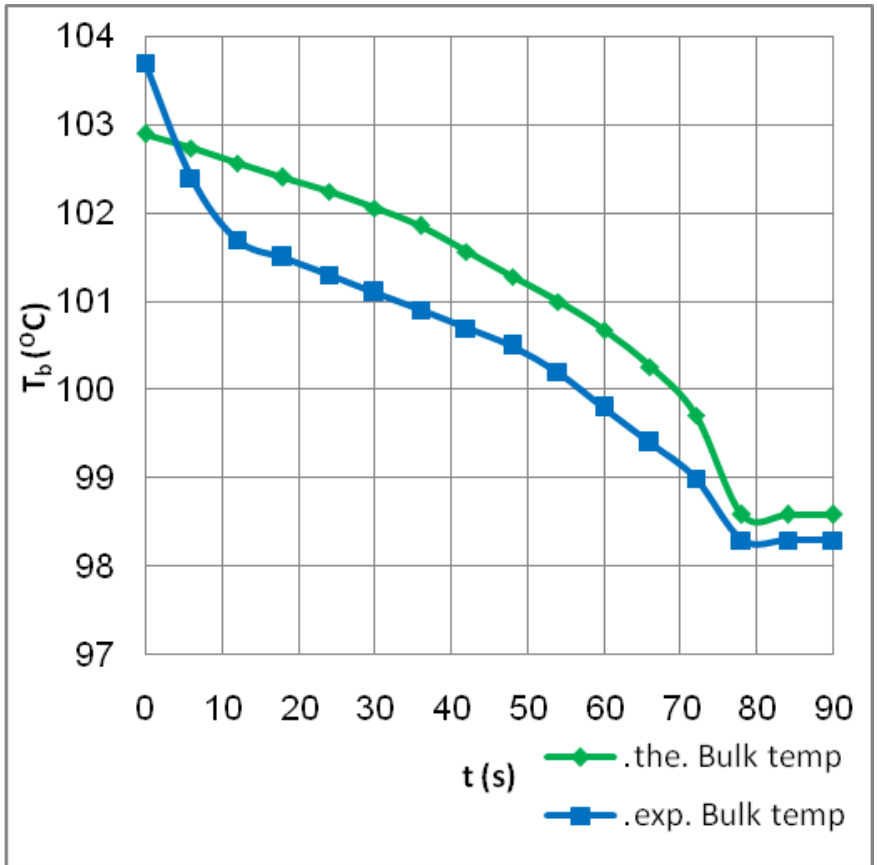

Fig (10): Theoretical and experimental bulk water temperature versus time at the end of the heat source, $(65 \mathrm{~cm})$ during pressure step reduction, $(\Delta \mathrm{TI}$ sub. $=200 \mathrm{C}$; $q=47100 \mathrm{~W} / \mathrm{m} 2 ; \mathrm{V}=0.121 \mathrm{~m} / \mathrm{s})$. 


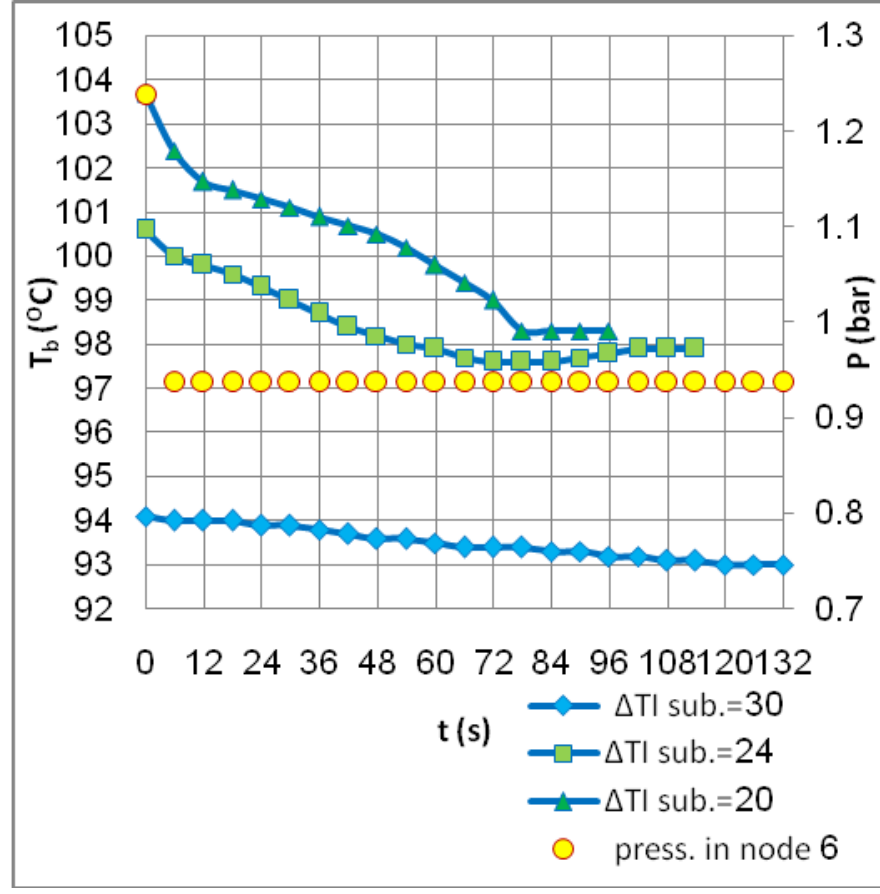

Fig (11): Experimental bulk water temperature versus time at the end of the heat source, $(65 \mathrm{~cm})$ during pressure step reduction, $\left(\Delta \mathrm{TI}\right.$ sub. $=30^{\circ} \mathrm{C}, 24^{\circ} \mathrm{C}$ and $\left.20^{\circ} \mathrm{C}\right)$.

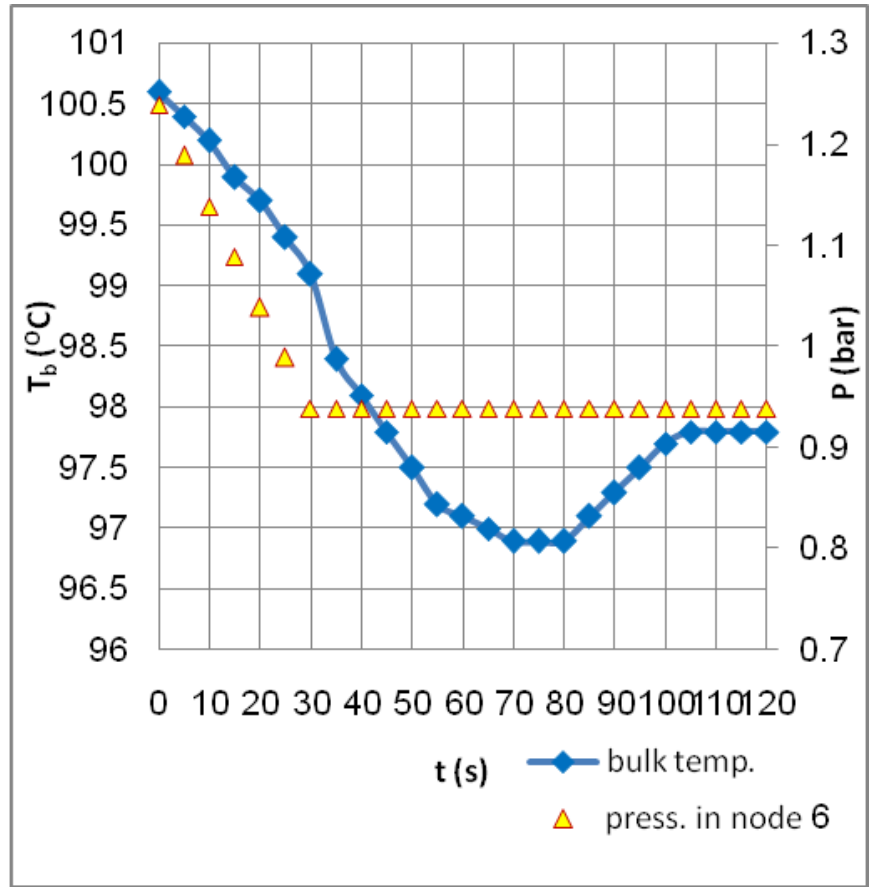

Fig (12): Experimental bulk water temperature versus time at the end of the heat source, $(65 \mathrm{~cm})$ during pressure ramp reduction $($ period $30 \mathrm{~s}),\left(\Delta \mathrm{TI}\right.$ sub. $=24^{\circ} \mathrm{C} ; \mathrm{q}^{\prime \prime}=45900$ $\left.\mathrm{W} / \mathrm{m}^{2} ; \mathrm{V}=\mathbf{0 . 1 2 1} \mathrm{m} / \mathrm{s}\right)$

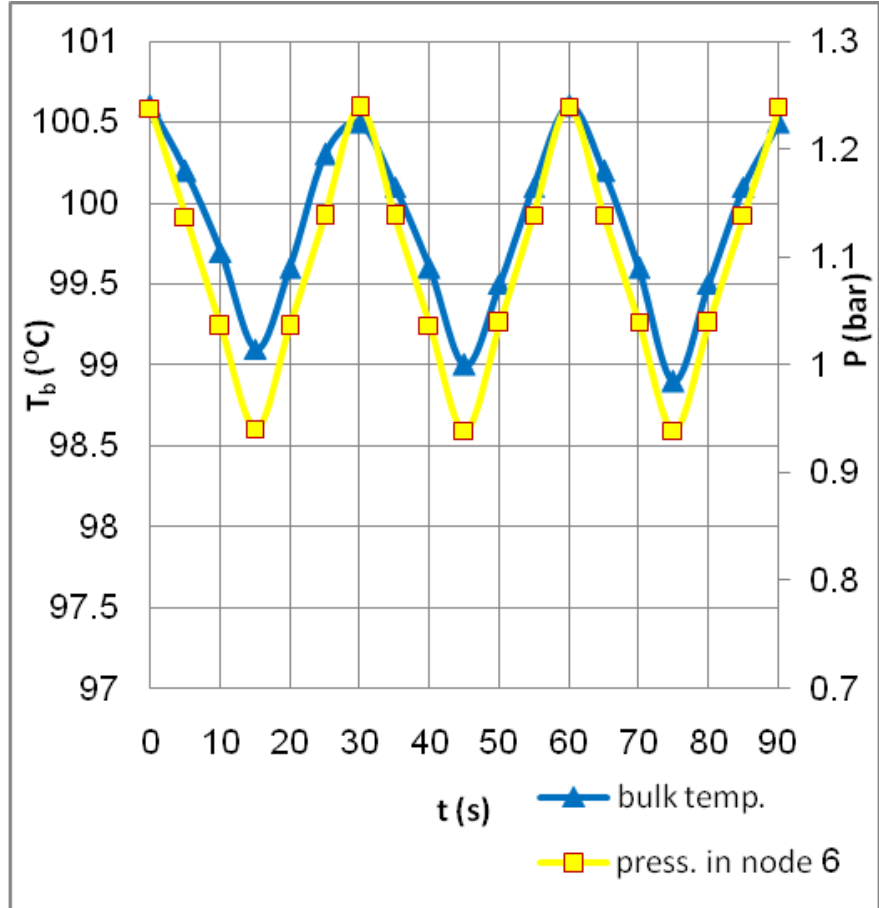

Fig (13): Experimental bulk water temperature versus time at the end of the heat source, $(65 \mathrm{~cm})$ during pressure sinusoidal change (period $30 \mathrm{~s}),\left(\Delta \mathrm{TI}\right.$ sub. $=24^{\circ} \mathrm{C}$; $\left.q^{\prime \prime}=45900 \mathrm{~W} / \mathrm{m}^{2} ; \mathrm{V}=0.121 \mathrm{~m} / \mathrm{s}\right)$.

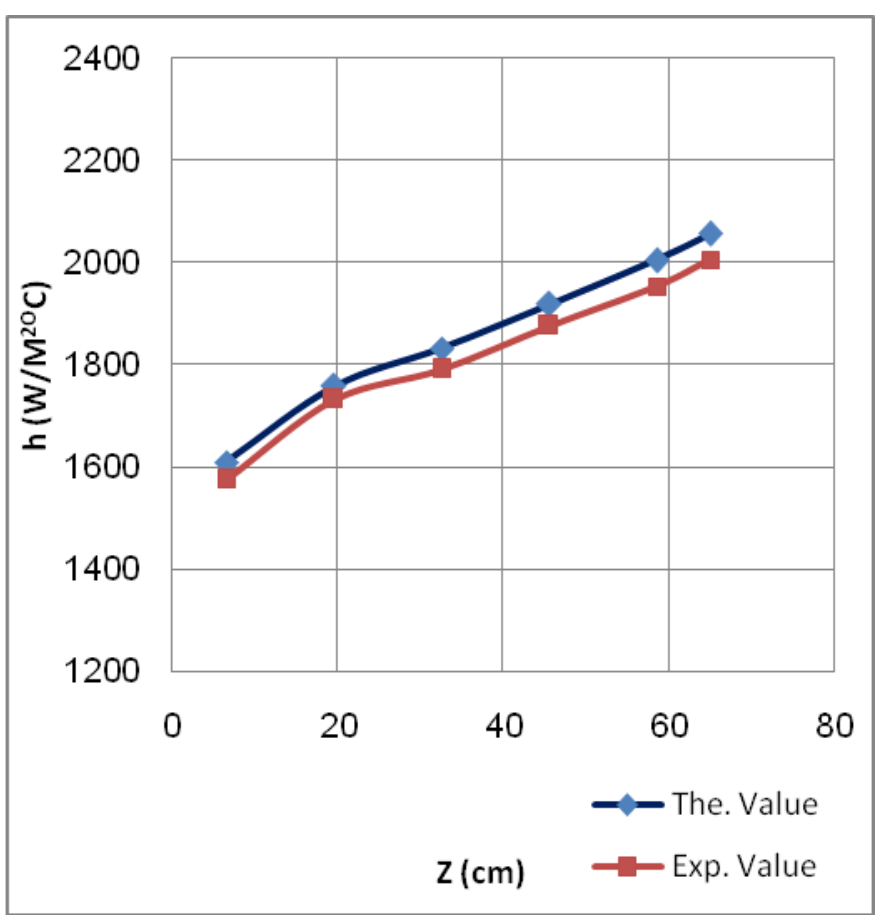

Fig (14): Experimental and theoretical heat transfer coefficient versus distance during steady state condition at ( $\Delta$ TI sub. $=20^{\circ} \mathrm{C} ; q^{\prime \prime}=47100$ watt $/ \mathrm{m}^{2} ; \mathrm{V}=0.121 \mathrm{~m} / \mathrm{s}$ ). 


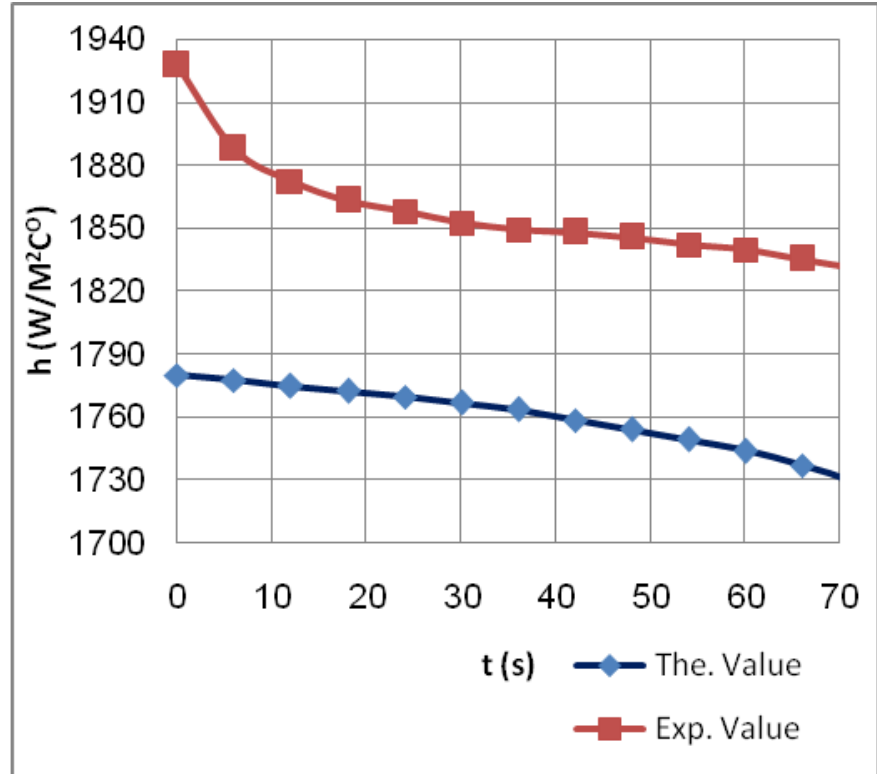

Fig (15): Experimental and theoretical heat transfer coefficient versus time at the end of the heat source, $(65 \mathrm{~cm}),\left(\Delta\right.$ TI sub. $=20^{\circ} \mathrm{C} ; q^{\prime \prime}=47100$ watt $/ \mathrm{m}^{2} ; V=0.121$ $\mathbf{m} / \mathbf{s})$.

\section{REFERENCES}

[1] Sarmad Aziz (2012) "Experimental Study of Power Increase Transient in Heat Generation Systems Simulated by Immersed Heat Source" A thesis submitted to the college of engineering university of Baghdad in partial fulfillment of the requirements for the degree of master of science in mechanical engineering.

[2] Collier, J. G. (1981) "Convective boiling and condensation" ( $2^{\text {nd }}$ end.) McGraw-Hill, New York.

[3] Kwang-Won Lee and Sang-Yong Lee. (1997) "An investigation of transition boiling mechanisms of subcooled water under forced convective conditions "Journal of Nuclear Engineering and Design, Vol. 177, PP. 25-39.

[4] K. E. GUNGOR and R. H. S. WINTERTON (1985) "A general correlation for flow boiling in tubes and annuli" Department of Mechanical Engineering,
University of Birmingham, Journal of heat and mass transfer Vol. 29, No. 3, PP. 351-358.

[5] V.Prodanvic, D.Fraser and M.Salcudean. (2002) "On the transition from partial to fully developed subcooled flow boiling"International Journal of Heat and Mass Transfer Vol.45, PP. 4727-4738.

[6] Hamid Saffari and Mehdi Ghobadi. (2010) "Calculation of convective boiling in a vertical tube at sub-atmospheric pressures"Australian Journal of Basic and Applied Sciences, 4(5), PP. 687-697.

[7] K.H. Bang, K.K. Kim, S.K. Lee and B.W. Lee (2011) " Pressure effect on flow boiling heat transfer of water in minichannels" International Journal of Thermal Sciences, Vol. 50 PP. $280-286$.

[8] Xiao Hu, Guiping, Yan Cai and Dongsheng (2011) " Experimental study of flow boiling of FC-72 in parallel minichannels under sub-atmospheric pressure" Applied Thermal Engineering, Vol.31, PP. 3839-3853.

[9] Dr.Harlan H.Bengtson,P.E. (2010) "Convection heat transfer coefficient estimation" www.SunCam.com, PP. $2-40$.

[10] M.A.Ebadian and Z.F.Dong. (2006) "Forced convection, internal flow in ducts "Chapter 5, Florida International University.

[11] M.M.El.Wakil. (1962) "Nuclear Power Engineering " McGraw-Hill Book Company, New York.

[12] A.W.Ezzat and H.M.Taki. (1988) Final safety report for $14^{\text {th }}$ Tammuz $5000 \mathrm{KW}$ reactor, INC, Iraq nuclear commission under the supervision of IAEA, paragraph 5.4 .

[13] LAEA Library Cataloguing in publication DATA. (2008) ) " Safety analysis for research reactors " International Atomic Energy Agency, Vienna, Safety Reports Series, No. 55. P.B Whalley (1987) " Boiling, Condensation \& Gas Liquid flow" Clarendon.

[14] P.B Whalley (1987) " Boiling, Condensation \& Gas Liquid flow" Clarendon. 